Revista Iberoamericana, Vol. LXXI, Núm. 211, Abril-Junio 2005, 539-553

\title{
EL HOMBRE ANARQUISTA DELINCUENTE
}

POR

Pablo Ansolabehere

Universidad de Buenos Aires

\begin{abstract}
Un juez, el egregio abogado Spingardi, quien me ha proporcionado gran número de datos para este estudio, me decía: "No he visto todavía un anarquista que no sea imperfecto o jorobado, ni he visto ninguno cuya cara sea simétrica”.
\end{abstract}

Cesare Lombroso

Después vinieron de Europa los enfermos, que formaron el socialismo agresivo, y los dementes, que predicaron la anarquía.

Francisco Sicardi

La primera cita pertenece a Los anarquistas, de Cesare Lombroso. En 1894, año de su edición, el autor ya es famoso en casi todo el mundo por sus teorías criminológicas, expuestas desde 1876 en El hombre delincuente. También en 1894 aparece en Buenos Aires Libro extraño, novela del médico argentino Francisco Sicardi. Aunque en realidad sería más exacto decir que ese año comienza a aparecer, ya que lo que hoy se conoce bajo el nombre de Libro extraño, de Sicardi, es una extensísima narración conformada por cinco volúmenes, el último de los cuales, Hacia la justicia, se publica por primera vez en 1902. ${ }^{1}$ De este volumen está tomada la segunda cita, que remite tanto al texto de Lombroso como a la ley 4144 -más conocida como ley de Residencia- sancionada por el Congreso argentino también en 1902, y que faculta al poder ejecutivo para la rápida sanción y expulsión de extranjeros indeseables. Como se sabe, el texto de esa ley está basado en un proyecto del escritor Miguel Cané.

Siempre veloz para detectar en los peligros foráneos las posibles amenazas internas, ya en 1899, con la edición del folleto Expulsión de extranjeros, Cané trata de justificar la necesidad de sanción de su proyecto apoyándose en el prolijo repaso de leyes similares (e incluso más duras) adoptadas en la mayoría de los países europeos y Estados Unidos para "extirpar de la tierra esa secta que tiende a convertirla en un infierno de odios y crímenes"

${ }^{1}$ Los nombres de esos cinco tomos son: Libro extraño, Genaro, Don Manuel Paloche, Méndez y Hacia la justicia. En 1910, en Barcelona, aparecen editados juntos los cinco tomos bajo el título de Libro extraño. 
(126). Esa secta es el anarquismo, el enemigo común e internacional que es necesario conjurar.

Extractos de un conglomerado discursivo mucho más amplio, el tratado criminológico de Lombroso, la novela de Sicardi y el proyecto de ley de Cané son ejemplos y parte de un proceso de criminalización del anarquismo que se verifica por esos años y que excede tanto las fronteras nacionales como las genéricas. Sin dudas la inserción de Argentina en el mercado mundial, con una política inmigratoria que posibilita la llegada de una importante camada de militantes anarquistas al país y una situación social que favorece la rápida expansión de su prédica, contribuye a la aceleración de esta variante del internacionalismo que experimenta la sociedad argentina de entre siglos.

El punto de partida de este trabajo es la constatación de un hecho que, por conocido, no deja de ser notable: una coincidencia discursiva que atraviesa indemne géneros y autores de lo más diversos. Ficciones, tratados, informes policiales, proyectos de ley, artículos y crónicas periodísticas no sólo insisten en la común condena del anarquismo; también el léxico, el estilo mismo, coinciden de tal modo que muchos párrafos podrían perfectamente trasladarse de un texto a otro de género absolutamente diferente sin que se pudieran percibir alteraciones o notas disonantes. ${ }^{2}$

Otro hecho notable es cómo el anarquismo logra armar en su contra un frente homogéneo conformado por autores de posiciones ideológicas divergentes y hasta enfrentadas. Indudablemente no son lo mismo el jefe de la policía de Buenos Aires, Coronel Ramón Falcón (orgulloso sostenedor de las fuerzas “conservadoras”) que el "sabio” Francisco Sicardi, decidido defensor de los beneficios de la inmigración europea. Incluso la antropología criminal, a la que automáticamente se asocia con los mecanismos represivos del Estado, es una disciplina que, en cierto sentido, puede ser encuadrada dentro de un impulso reformista enfrentado a las posiciones políticas más duras y conservadoras frente al fenómeno de la criminalidad. En el comienzo de Los anarquistas, Lombroso hace un repaso crítico de la situación social explosiva derivada de una serie de injusticias achacables a los gobiernos europeos, y no duda en alinearse con la plataforma política del socialismo.

Por supuesto esto no niega la alianza de la antropología criminal con el Estado y su funcionamiento como la disciplina que, apelando a su estatus científico, mejor justifica una serie de procedimientos coercitivos que, lejos de atenuar el rigor represivo del Estado, lo perfeccionan. Lo que me interesa, en todo caso, es señalar cómo una manifiesta heterogeneidad ideológica y discursiva se disuelve y homogeneiza gracias a esa "prenda de unión” en la que se convierte el anarquismo. La razón de este efecto unificador indudablemente tiene que ver con las propuestas del anarquismo que, más allá de sus divergencias y grupos enfrentados, coincide en condenar sin reparos la maquinaria estatal y señala con insistencia la necesidad de su destrucción total. Pero lo que convierte al anarquismo en una amenaza no es sólo el contenido de su prédica, sino sobre todo una notoria presencia pública de la que los atentados contra figuras públicas de Europa y

2 Algunos ejemplos argentinos, además de la novela de Sicardi y el folleto de Cané, son el "Estudio de antropología criminal” de Francisco de Veyga, el informe del jefe de policía Ramón Falcón (Policía de Buenos Aires 1909) y el artículo de Cané que figuran en la bibliografía. 
América-conocidos como “propaganda por el hecho”-resultan su aspecto más espectacular y el mejor aprovechado por sus detractores, pero no el único ni, seguramente, tan inquietante como el hecho de su importante influencia en las luchas y posturas radicales del movimiento obrero.

Hacia fines de siglo, el anarquismo se convierte en un fenómeno digno de consideración al que se estudia sobre todo como una enfermedad contagiosa que hay que descifrar para poder controlar. En ese sentido no es de extrañar que el camino elegido para hacerlo conduzca, más que a la doctrina, a sus sostenedores. El fenómeno del anarquismo se desentraña estudiando a los anarquistas. Esto no quiere decir que no se discutan los fundamentos teóricos del anarquismo. De hecho, en muchos textos sobre el fenómeno anarquista se hace un repaso de esos fundamentos con el propósito de demostrar su improcedencia, sus aberraciones, sus errores; pero en general se trata de un repaso sumario que, como en el texto de Lombroso, se liquida rápidamente para concentrarse en lo que realmente importa: los anarquistas, a los que, al criminalizarlos, se los utiliza como el principal argumento en contra de la doctrina.

Médicos, contemporáneos, Lombroso y Sicardi, uno desde la antropología criminal y el otro desde la narrativa de ficción, escriben y se inscriben en este proceso de criminalización del anarquismo. Lo que me interesa aquí es analizar, a partir de sus textos, cómo se implementan en la escritura ciertos mecanismos de criminalización, de qué manera contribuye a tal implementación ese fenómeno de ósmosis discursiva que se verifica entre la literatura científica (en especial la criminológica) y la ficción, y, sobre todo, cómo se construye la figura del anarquista delincuente, personaje que es descrito como individuo (y por lo tanto narrado como biografía) y tipificado (y por lo tanto convertido en figura de conjunto) a partir de ciertos rasgos "científicamente” constatados. Operatoria a la que habrá que agregarle otro movimiento complementario, también pendular: el tratamiento "psicológico" de su manifestación grupal en la muchedumbre.

\section{L'UOMO DELINQUENTE}

En 1876 aparece la primera edición de El hombre delincuente, de Cesare Lombroso. Pese a que poco tiempo después sus hipótesis centrales comienzan a ser dura e implacablemente cuestionadas (sobre todo por los representantes de la escuela criminológica francesa) y de que hoy sus premisas han sido descartadas, la aparición del libro de Lombroso implicó un giro sustancial en la mirada sobre la criminalidad.

Su aporte decisivo a la criminología consiste en desplazar el punto de interés del delito (escuela clásica) al delincuente. Lo realmente existente y, por lo tanto, plausible de estudio, medida y consideración es el criminal. La pena que el juez establece para el que transgrede la ley, entonces, debe considerar no al crimen en sí mismo, aislado de la realidad en un código, sino al hombre concreto que lo comete.

Las críticas que recibe Lombroso no apuntan a este cambio de perspectiva, sino a los fundamentos de su antropología. Básicamente: su convicción de que la razón de la tendencia al delito se encuentra en el atavismo, y que el criminal nato (individuo condenado inevitablemente, por ese atavismo que lo domina, al delito) puede ser reconocido por ciertos estigmas físicos. 
Una de las principales razones del éxito inicial de esta nueva disciplina es que surge en respuesta directa a una necesidad estatal vinculada con el control de la criminalidad. La explosión demográfica en las grandes ciudades del mundo desborda las formas tradicionales de vigilancia y exige la creación de nuevos mecanismos de control social. La prensa difunde esta sensación de desborde y se impone la necesidad de medidas urgentes para detener lo que es visto, en las últimas décadas del siglo, como un avance incontrolado del delito. La antropología criminal surge en respuesta a esta demanda y se presenta no sólo como una disciplina capaz de estudiar mejor la criminalidad, sino también como la más apta para detener ese desborde y prevenirlo. El ejemplo más gráfico -y también el más débil- de esta confianza es la creencia de que el sujeto peligroso (el criminal nato) puede ser reconocido, antes de tener la posibilidad de concretar esa peligrosidad, por sus rasgos y sus medidas, síntomas inequívocos de su atavismo criminal.

Es esta misma vinculación con las necesidades estatales de control lo que motiva el interés de Lombroso, primero por el delito político y, más tarde, por el caso puntual de los anarquistas. Su propósito es leer el fenómeno del anarquismo desde su teoría sobre el delito y de encuadrar a los anarquistas en su famosa grilla de tipos criminales.

Por supuesto la operación no es tan sencilla como parece. En primer lugar hay que aclarar que, pese a las duras críticas que desde el anarquismo recibió este texto, la antropología criminal gozaba de prestigio incluso entre los propios anarquistas, seguramente en virtud de su aura científica, pero también porque muchos criminólogos no dejaban de señalar la miseria y la marginación social como un caldo de cultivo ideal para el surgimiento del delito. ${ }^{3}$ Hay incluso en el texto de Lombroso pasajes que pueden sorprender por la crítica al sistema social de su época. Sin embargo, esta crítica, que podría conducir a una explicación primordialmente social de la criminalidad -que justificaría hasta cierto punto la existencia del anarquismo- se diluye ante la enfermedad congénita del anarquista delincuente como motivo determinante de su tendencia al delito.

Como se dijo, el punto de partida de Lombroso es su propia teoría del hombre delincuente. Ésta es la base científica que -pese a algunos cuestionamientos- legitima su mirada sobre el anarquismo. Ejercer esta mirada desde una perspectiva criminológica es para Lombroso, padre fundador en la materia, otro modo de autorizar su análisis de un fenómeno político inicialmente ajeno a su especialidad. El hecho de que Lombroso admita que se ha interesado en el anarquismo por la cantidad de sus seguidores no sólo demuestra cierto oportunismo, sino que justifica la utilidad de un estudio como éste, recordando que el anarquismo es visto, por sus ideas, sus atentados y, sobre todo, por la cantidad de sus seguidores, como una verdadera amenaza para el orden social.

Esta conjunción de una ideología y de un número considerable de sostenedores es lo que estructura el texto, que comienza con un análisis de los postulados del anarquismo para seguir con el estudio más detallado de sus seguidores. En el primer paso, realizado

\footnotetext{
${ }^{3}$ Paradojas argentinas: Pietro Gori, el intelectual italiano que contribuyó en forma decisiva a la consolidación del anarquismo en Argentina, también fue clave en el surgimiento y desarrollo de la antropología criminal en el país. Gori fue el fundador y director de Criminalogía Moderna, revista en la que colaboraron los más reconocidos criminólogos europeos (sobre todo los italianos) y en la que también escribieron José M. Ramos Mejía, José Ingenieros, Antonio Dellepiane, Luis María Drago, JuanVucetich, Osvaldo Piñero, entre otros.
} 
sumariamente (y lleno de errores conceptuales), Lombroso no sólo intenta demostrar los "absurdos" de la doctrina, sino que, al calificar el deseo de los anarquistas de volver a formas arcaicas de organización social como un rasgo inequívoco de atavismo, comienza el proceso de criminalización que va a ser explícito en la segunda etapa, al focalizar el análisis en los hombres anarquistas.

Casi todo el texto está dedicado a ellos, fundamentalmente a quienes han cometido algún delito político, porque, obviamente, es el camino que mejor conduce a la criminología. De ahí en más el texto se organiza a partir de todos los rasgos que, según Lombroso, demuestran criminalidad: “jerga”, tatuaje”, “sentido ético”, “lirismo”, “neofilia”, etc., y, sobre todo, de las características privilegiadas: "histerismo, epilepsia y locura”. Con una disparidad de fuentes notable (que incluye fragmentos novelescos de Emile Zola, recortes periodísticos, confidencias de amigos, datos de colegas y poquísima observación directa) Lombroso va cubriendo con casos de anarquistas -y también con los de terroristas de diverso signo político- todos los lugares previstos en su esquema del delito. Dentro de la heterogeneidad que caracteriza su discurso, hay un género que se privilegia: el caso, esa especie de biografía del delincuente que corrobora un tipo previamente formulado. Si la biografía de Caserio le sirve, por ejemplo, para demostrar su pertenencia al grupo de los delincuentes pasionales, la de Ravachol encaja perfectamente, pese a las aparentes motivaciones políticas de sus crímenes, con el tipo del delincuente nato.

A través de la prolija inclusión de sus sostenedores en el panteón de cada uno de los tipos delincuentes, Lombroso ensaya y legitima la criminalización de ese conjunto de ideas llamado anarquismo, al mismo tiempo que explica el recrudecimiento de una tendencia al delito por la incidencia malsana de esa doctrina política. Por eso no resulta extraño que hacia el final del libro, Lombroso hable directamente de la "plaga" de la anarquía y que la conclusión de su estudio se titule "Profilaxis". Su conclusión utilitaria completa el diagnóstico que justifica la necesidad de exclusión con las medidas más adecuadas para hacerla efectiva.

Lombroso aconseja desechar la pena de muerte ya que, aunque no la descarta, considera que la mayor parte de los anarquistas (salvo Ravachol, Pini y algún otro) no son criminales natos. ${ }^{4}$ Recomienda, entonces, otras medidas más "humanitarias" -que explícitamente Lombroso vincula con los postulados del partido socialista-que consisten en mejorar las condiciones de vida de la clase obrera, introducir reformas legales que contribuyan a esa mejora y cambiar una educación que no hace sino glorificar la violencia. Pero, hasta tanto esas medidas no se implementen, sugiere otras más perentorias y prácticas: restricción de la libertad de prensa, control policíaco nacional e internacional, reclusión en manicomios (más eficaz que la pena muerte, porque, como explica Lombroso, los locos producen risa, no mártires) y deportación.

\section{LETRA DE MÉDICO}

El anarquismo es, como el crimen, un fenómeno internacional: se manifiesta en diversas partes del mundo, sus seguidores, empujados por la miseria y, sobre todo, por la

4 “No soy yo, ciertamente, enemigo de la pena de muerte; pero sólo la acepto tratándose de criminales nacidos para el mal, cuya vida sería un constante peligro para la de muchos hombres honrados” (63). 
policía, emigran y, como “el capital no tiene patria”, pueden actuar con sobrada causa en cualquier nación. Alrededor de 1900, la forma más publicitada de esa actuación es, justamente, la "propaganda por el hecho”. El caso del anarquista italiano Santo Caserio, asesino del presidente francés Sadi Carnot, es uno de sus ejemplos más elocuentes. Otro caso de internacionalismo, aunque de diferente signo, es el de Ignacio Monges, homicida frustrado del presidente argentino Julio A. Roca. Monges, nacido en la provincia argentina de Corrientes, no es un delincuente traído por la inmigración europea. La sorprendente mención del caso Monges en Los anarquistas, junto con los célebres Caserio o Vaillant, demuestra, además de la desprolijidad de Lombroso (el anarquismo de Monges es inexistente), la rápida difusión de la antropología criminal en América (en un movimiento tan amplio y veloz como el del propio anarquismo), y la fluida comunicación de sus principales representantes con sus pares europeos (lo que explica la presencia del caso Monges en el libro de Lombroso).

Estas variantes del internacionalismo se vinculan directamente con algunos de los temas que más preocupan a la dirigencia argentina de fin de siglo: la llamada "cuestión social” y la disputa entre inmigración y nacionalidad. Y también tienen que ver con el cruce intenso entre discurso científico y ficcional que determina ciertas formas de entender y practicar la literatura argentina. En ese entramado se inscriben Sicardi y su novela. Sicardi, porque él mismo integra la nutrida camada de médicos-escritores que irrumpe en la literatura argentina desde $1880 .{ }^{5}$ Este fenómeno, que puede ser visto como la continuación de un rasgo que definió a los escritores argentinos del siglo xix, para quienes "la categoría de escritor era subsidiaria” (Jitrik 89) es, por otro lado, el resultado lógico del acercamiento intenso entre discurso médico y narrativa de ficción. Desde luego, el naturalismo que irrumpe en la Argentina de los ochenta es una muestra de esa comunión. Pero además, y no solo en los textos naturalistas, se da una creciente incorporación de ciertos temas que directa o indirectamente tienen que ver con el saber médico-criminológico, al mismo tiempo que puede observarse la irrupción de la figura misma del médico (a veces como naturalista, a veces como inventor) convertido en personaje central de las ficciones de la época.

Esta cercanía también alienta un proceso de contaminación discursiva que posibilita la incorporación de ciertos géneros de la escritura médico-criminológica a las ficciones y un verificable uso de estrategias narrativas provenientes de la ficción en ese discurso médico-criminológico. ${ }^{6}$ La novela de Sicardi es un ejemplo privilegiado de esa simbiosis: la mitad de sus protagonistas son médicos, la enfermedad es objeto permanente de interés

\footnotetext{
${ }^{5}$ Algunos nombres: Eduardo Wilde, Antonio Argerich, Manuel Podestá, Ricardo Gutiérrez, Eduardo Holmberg.

${ }^{6}$ El ejemplo más notorio de la relación entre antropología criminal y ficción es la relación entre Lombroso y Zola. Lombroso se sirve de varios personajes de Zola para ilustrar sus teorías y, a la vez, Zola se inspira en la descripción del hombre delincuente para la escritura de La bestia humana. Pero hay otros ejemplos más sorprendentes de esa relación. En Drácula, de Bram Stoker (1897) el personaje de Nina describe al conde de la siguiente manera: "The Count is a criminal and of criminal type. Nordau and Lombroso would so classify him, and qua criminal he is of imperfectly formed mind” (300) Asimismo la descripción inicial del conde hecha por Jonathan Harker sigue casi al pie de la letra los rasgos que Lombroso atribuye al criminal nato.
} 
y, al mismo tiempo, clave de su metafórica, y el caso es la forma que sirve de modelo para los relatos de vida que abundan en la novela.

En Hacia la justicia se pretende hacer un examen y un diagnóstico de la sociedad argentina de fin de siglo entendida como cuerpo. Es un cuerpo social amenazado por la enfermedad. En este sentido la novela aparece como el género más adecuado para mostrar el verdadero carácter de esa enfermedad y también el camino de la cura y la prevención. La estrategia de Sicardi para plasmar narrativamente este asunto consiste en poner en acción a ciertos personajes que condensan esquemáticamente los rasgos de los agentes que amenazan con destruir el cuerpo social, pero también a aquellos que pueden funcionar como sus anticuerpos.

EL HOMBRE DE LA MULTITUD

Entonces, en medio de aquel tumulto, se levantó una voz que estremeció a todos. Era de un hombre joven. Su cara se veía a ratos en las súbitas brillazones. Su piel estaba lívida y macilenta, el ojo feroz y con insolencias de burdel. El crimen enronquecía la palabra, que tenía un eco estridente. (Sicardi 417)

Este párrafo marca la irrupción del individuo amenazante en la historia. Todavía no se sabe quién es, pero el hecho de aparecer rodeado por la multitud es suficiente para dar a entender su grado de peligrosidad. Ese “tumulto” del que surge es la muchedumbre pobre y silenciosa que, empujada por la inundación invernal, abandona sus hogares del suburbio y avanza hacia el centro de la ciudad. La escena muestra muy claramente la esencia de la amenaza, radicada en esa comunión entre el orador de palabra criminal y la multitud a la que se dirige y se propone dirigir. La dramaticidad de su irrupción está dada tanto por el efecto lumínico como por esa comunicación entre el hombre capaz de estremecer y la masa dispuesta a seguirlo.

En su descripción, plagada de subjetivemas, aparecen los tópicos de la criminalización: enfermedad, ferocidad (rasgo de atavismo) centrada en el “ojo”, órgano aquí asociado con el sitio emblemático de la "mala vida”, el burdel. Y todo, a su vez, reforzado por la actividad criminal que se ejercita a través de la palabra. Él es, antes que un cuerpo, una "voz" que estremece "a todos".

Lo que sigue a esta descripción es la reproducción de su palabra. Se trata de una arenga violenta en contra de la clase rica que mantiene la desigualdad social, y también contra la muchedumbre que, en lugar de destruir a sus explotadores, acepta pasivamente su destino miserable. Como para no dejar dudas (muy pocas veces las deja Sicardi) sobre la violencia y la amenaza encarnadas en el orador, al finalizar su arenga se lo ve agitar-siempre iluminado por los relámpagos- un tubo de metal que no es otra cosa que una "bomba de dinamita” (418). Discurso y gestualidad se unen para concluir en la nominación del personaje aún sin nombre. A esa amalgama de enfermedad, multitud y discurso criminal, se le adosa una denominación política que sirve para nombrar y definir al orador: él es "el anarquista”.

Si bien el héroe ejemplar que propone la novela es Elbio Errécar, el verdadero protagonista (secundado por su novia-prostituta Goga y por la multitud) es el anarquista; 
la trama gira alrededor del caso Germán Valverde. Su biografía es el centro de la historia y el tipo criminal designado con el nombre de "anarquista" es el molde que guía la elaboración minuciosa y recargada de esa biografía. La historia de su vida -su casoejemplifica y corrobora el tipo en el cual se inspira. Por supuesto, el marco novelesco, ficcional, opera cambios sobre el género, pero -y esa es una de las apuestas de la ficcióncon la posibilidad de mejorar su eficacia. La ficción novelesca permite indagar de otra manera y llegar a lugares a los cuales la escritura médico-criminológica no tiene acceso. Y además es, por la misma razón, capaz de “elegir” al personaje perfecto para encarnar esa abstracción llamada "tipo criminal”, con la cual nunca encajan del todo los casos concretos que ofrece la realidad.

Por otro lado, también es importante señalar aquí que quienes practicaban la escritura médico-criminológica no dejaban de recurrir a estrategias ficcionales en la elaboración de sus casos. Y que, asimismo, las fronteras entre los géneros que conformaban la literatura nacional eran lo suficientemente flexibles como, por ejemplo, para que un mismo escritor se moviera con pareja comodidad por el espacio de las novelas y de la literatura médica, o para que un texto publicado originalmente en una novela pudiera ser extraído del mundo de la ficcíón e insertado como un texto autónomo en una publicación científica, sin que se discutiera su pertenencia a ese otro espacio. ${ }^{7}$ A estos ejemplos podemos agregar el hecho de que varias ficciones de la época son leídas y debatidas como documentos científicos. En este sentido es interesante leer la crítica que hace José Ingenieros de la novela de Sicardi. Analizando a los personajes de Hacia la justicia, al llegar a Germán, Ingenieros elogia a Sicardi porque con él ha logrado encarnar el tipo psicológico adecuado del meneur.

Veamos cómo lo hace. Luego de la irrupción del personaje, el narrador procede a elaborar, en el capítulo que lleva su nombre, la biografía del anarquista. En su construcción del caso Germán, Sicardi inicialmente se aparta de los parámetros adjudicados por Lombroso al criminal nato para explicar el origen de su tendencia al delito (tendencia radicada en los impulsos atávicos) y, siguiendo a otros criminólogos (entre ellos el propio Ingenieros) prefiere combinar la herencia con la influencia del medio y la educación. Su padre es "una basura infame", un asesino; su madre, una prostituta; el medio donde se cría es la pieza del conventillo y, más tarde, la calle. No conoce amor de madre ni quién ha sido su padre y desde niño se acostumbra a recibir golpes en lugar de caricias. Pero no será su única escuela la calle porque un día, inesperadamente, y cumpliendo la voluntad de un misterioso protector que resulta ser su padre, es ingresado en uno de los mejores colegios de Buenos Aires. Sin embargo el golpe novelesco de la suerte no logra torcer el destino (del) incorregible. Es demasiado tarde para mitigar años de desamor, y muy poco puede hacer un colegio para interferir en la herencia del crimen. Los resabios del conventillo y de su prosapia, ya alojados en la sangre de Germán, se manifiestan en la forma de una tuberculosis no disimulada. ${ }^{8}$

${ }^{7}$ Tal es el caso de las Memorias de Enrique Valverde para su hijo, aparecidas originalmente, como veremos, en Hacia la justicia, y publicadas luego, con algunos cortes, en el número 2 de los Archivos de Psiquiatría, Criminología y Ciencias Afines (1903), bajo el título de "La vida del delito y la prostitución. Impresiones médico-literarias".

${ }^{8}$ En el prólogo, Sicardi informa que Germán y su padre pertenecen al grupo de los "locos morales”, categoría criminológica equivalente a la del “delincuente nato” de Lombroso. 
El relato de esos años de colegio se limita a su aprendizaje nocturno, lejos de las aulas, en el espacio privado de su cuarto. Germán no duerme, lee. Y lee textos “prohibidos en el colegio" (424), libros de criminales y literatura anarquista (que vienen a ser lo mismo). La representación de esta escena de lectura y aprendizaje del mal consiste en reproducir eso que Germán lee y en describir los trastornos que esa lectura le provoca:

Una ira violenta se apoderaba en aquellas lecturas del corazón de Germán. Era violento, irascible, indisciplinado (424).

Entonces se retira al estudio para volver a sus autores sombríos y el pesimismo demoníaco le aferra de nuevo el corazón. De cuando en cuando tosía. Una vez sintió un gusto salado en la boca. Era un esputo con sangre. No hizo caso y bajó de nuevo la cabeza sobre sus autores sombríos. (430)

Ese aprendizaje se completa con otro texto que Germán recibe y lee en el colegio: las Memorias de Enrique Valverde para su hijo, un manuscrito de "páginas corroídas, con manchas" (451); sucio como la materia de que trata. Herencia y pedagogía se unen en estas “memorias perversas" (461) del padre médico, escritas especialmente para mostrar la podredumbre del mundo y pedirle al hijo el cumplimiento del mandato de su sangre, orgullosamente alimentada por el crimen.

Curiosamente, la herencia y el atavismo malsano de su progenie triunfan en Germán gracias, sobre todo, al poder pedagógico de la palabra. Al terminar de leer las Memorias Germán decide que ha concluido su educación, abandona el colegio y vuelve a la calle para llevar adelante el mandato homicida de su padre: unirse al "ejército de vengadores que blanden en lo alto la dinamita” para, como le aconseja al final, no perdonar ni manchar "con vulgares deliquios la soberbia homicida de tu prosapia” (480). Herencia, medio adverso, enfermedad, lecturas perniciosas, los ingredientes justos que se necesitan para la creación del delincuente anarquista incorregible, se refuerzan con el mandato paterno que corrobora la alianza homicida de degeneración y anarquismo. ${ }^{9}$ Ingredientes que al conjugarse cierran la primera etapa del caso Germán. La segunda comienza y concluye con la multitud.

INFAME TURBA

Como ya se dijo, la constitución de Germán como individuo peligroso cobra real significado cuando su figura se recorta sobre el inquietante fondo de la multitud.

La multitud -sobre todo la urbana- se convierte en uno de los objetos predilectos de las ciencias sociales en la segunda mitad del siglo xIx y también, puede decirse, se consolida como un nuevo personaje literario.

El texto clásico sobre este tema es Psicología de las multitudes (1895), de Gustave Le Bon, cuyo correlato vernáculo será Las multitudes argentinas (1899), de José María Ramos Mejía, texto que debe ser leído no sólo como una muestra de la sintonía de los

${ }^{9}$ Su cinismo extremo y su condición de médico convierten a Enrique Valverde en el medium ideal para mostrar las peores lacras sociales pero sin que la podredumbre salpique al narrador. 
intelectuales argentinos con los objetos de estudio de las ciencias sociales europeas (el libro de Le Bon es el representante más reconocido de una extensa serie que incluye, entre otros a La multitud delincuente (1891), de Scipio Sighele) sino también como un intento de respuesta (siguiendo en líneas generales los postulados epistemológicos que esa bibliografía europea propone) a un dato de la realidad argentina que también ha comenzado a ser visto como problema. Buenos Aires hacia fin de siglo ha sido capaz, con la inestimable ayuda del proceso inmigratorio, de engendrar sus propias multitudes y este dato visible de la realidad no pasa inadvertido tampoco para la literatura.

Lo amenazante de la multitud es, junto con el número, su imprevisibilidad. Además, la multitud es una suerte de torbellino donde la individualidad -esto es, la capacidad de raciocinio individual-se diluye en el vértigo que impone la muchedumbre, movida por el puro impulso pasional. Es esta visión de la multitud la que permite equipararla con otros seres estigmatizados por el predominio de los impulsos pasionales sobre su voluntad, como los criminales, los epilépticos o, incluso, las mujeres. Siguiendo a Le Bon, Ramos Mejía explica que, debido a esta irracionalidad, la muchedumbre solo puede pensar a través de imágenes; únicamente ellas pueden atemorizarla o seducirla. Por eso, entonces, la muchedumbre merece ser estudiada para saber cuál es el mejor modo de neutralizarla y, sobre todo, de dirigirla. Profetiza Le Bon que solo quien conozca el arte de impresionar la imaginación de la muchedumbre será capaz de conocer el arte de gobernarla. De ahí que, en esta suerte de dialéctica entre el individuo y el grupo, sea fundamental la figura del meneur, la del conductor capaz de determinar la dirección de la multitud.

Hacia la justicia es un texto que ficcionaliza de forma obsesiva esta preocupación: puede decirse que la novela comienza donde el texto de Ramos Mejía termina. Recordemos este final: “Temo que el día que la plebe tenga hambre, la multitud socialista que se organice sea implacable y los meneurs que la dirijan representen el acabado ejemplar de esa canalla virulenta que lo contamina todo” (Ramos Mejía 347). Pues bien, en Hacia la justicia ese día ha llegado. El hambre y la miseria ponen en movimiento a la muchedumbre obrera que, acosada por la inundación, se desplaza de los barrios al centro de la ciudad. Una muchedumbre que encuentra a ese meneur contaminador que temía Ramos Mejía y que, para colmo de males, no es socialista sino anarquista.

Sicardi trabaja ese temor y con ese temor. Trabaja ese temor porque el rasgo primario de la multitud obrera -lo que va creando la tensión narrativa- es su presencia amenazante, expresada, además, en una dirección de clase muy nítida: "la falange va llegando con su siniestro serpear homicida a morder la garganta o los pulmones de los hijos señorales” (410). Y trabaja con ese temor, porque es evidente que la preocupación mayor del relato es tratar de conjurarla. Sicardi hace presente a esa multitud para desmenuzarla y buscar una alternativa neutralizante y superadora. Por un lado apela a todo el repertorio existente para designar a la multitud, lo que le permite establecer distinciones, jerarquías, es decir un cierto orden. Por otro, y en un movimiento paralelo a éste, comienza, una vez colocada en escena la masa obrera, a clasificar a los integrantes de cada uno de los tres grupos en que se dividirá esa inicial muchedumbre, además de asignarle a cada uno su meneur claramente tipificado. La ecuación es así: hay dos grupos sectarios enfrentados a muerte y que, por ese sectarismo que los define, están destinados al fracaso: la muchedumbre anarquista y 
la católica. Y en el medio, expresando una tercera posición triunfante, la muchedumbre de los “obreros libres”, liderada por el héroe de la novela, el médico Elbio Errécar.

Por supuesto que esa equidad negativa de ambas “sectas”, la católica y la anarquista, es sólo aparente. La esterilidad y el fanatismo de la silenciosa muchedumbre de los obreros católicos no se compara en grado de peligrosidad con la ruidosa multitud anarquista. Los términos a los que recurre Sicardi para describirla son elocuentes: "turba”, "tumulto", “tropel”, "baraúnda”, “enjambre”, "horda”. Todos ellos aluden, en diferentes grados, a la movilidad desordenada y al sonido estridente, signos inequívocos de su salvaje potencial dañino. Es por eso que ese catálogo degradante de la muchedumbre se completa con todos los síntomas que sirven para definir al criminal nato y, en general, al enfermo. Por empezar, la multitud misma es, según se dijo, el lugar ideal para el surgimiento de los impulsos atávicos del hombre. En su seno, que obtura el raciocinio, despierta el "mal salvaje” en toda su potencia destructora. Unido a ese atavismo, aparece la enfermedad, sobre todo aquella con la que más se asocia la criminalidad. Describe el narrador: “de lejos se sentía venir [...] una enorme masa negra, avanzando entre las trepidaciones epilépticas” (519, énfasis mío).

A este proceso de criminalización de la muchedumbre epiléptica anarquista hay que añadirle el estudio minucioso de cómo está compuesta esa multitud. En este punto el narrador es capaz de congelar la imagen de esa masa ruidosa y móvil para diseccionarla. Ahí vemos aparecer, entonces, la confirmación de sus presunciones: esa muchedumbre está integrada, en su mayor parte, por los restos, los “detritos” (como dice) sociales: borrachos, enfermos, idiotas, epilépticos, prostitutas:

\begin{abstract}
un aura de manicomio epiléptico con su síntesis dolorosa de fronterizos; los casi idiotas de cara abotargada y labio caído, los impulsivos de resuelto ademán y brincos de macho cabrío; los perseguidores y perseguidos por la quimera sombría, que escuchan, en las visiones de las malas bebidas, criminales consejos, y uno que otro megalómano de risueño talante e imperiales aposturas, soñador de glorias tribunalicias y de imposibles tesoros. Aquí y allá fragmentos del gran hospital quejumbroso y sucio, sonando las toses roncas en las gargantas dilaceradas por las mordeduras del tubérculo. (535)
\end{abstract}

Pero hay una palabra más que necesariamente debe completar el repertorio que define a la turba anarquista y a sus integrantes: la huelga. Se produce aquí un curioso desplazamiento semántico que transforma a una metodología de lucha obrera en otro sustantivo colectivo que se integra a la serie sinonímica de muchedumbre. La turba anarquista es la huelga o mejor, como dice el texto, es "esa gangrena que se llama huelga" (490). En este sentido "huelga" es el término que corona esa serie, porque es el que mejor representa su amenazante poder subversivo, la verdadera razón-política-de su peligrosidad. A ese cuerpo que es la nación le ha surgido una gangrena llamada huelga. Huelga es turba, es tumulto, es horda; pero, al mismo tiempo, inmovilidad, parálisis, enfermedad, muerte del cuerpo de la nación. Huelga es, en definitiva, el colectivo exacto para definir la alianza de muchedumbre y anarquismo y para medir los alcances de su peligrosidad. Por eso, desde un punto de vista criminológico la huelga es el estadio superior de la multitud, su uomo delinquente, su criminal nato. 
Profilaxis

Pero la criminalización del anarquismo no está completa si no se explica cómo conjurarlo. Para hacerlo hace falta también indagar su origen, descubrir de dónde sale, recorrer sitios y territorios. Está claro que la muchedumbre anarquista procede fundamentalmente del suburbio, de las fábricas, de los hospitales, del prostíbulo, del conventillo, de las cárceles y de los manicomios. Pero sus conductores (que originalmente también proceden de esos lugares) se han formado y -literalmente- han salido de bajo tierra, porque el sitio verdadero del anarquismo es el sótano, albergue ideal de la sociedad secreta. Fue allí donde, antes de ingresar en el colegio, Germán recibió su primera educación: "asistía a reuniones de criminales, en los antros tenebrosos donde se estudia y medita el delito" (422). Esas aulas oscuras y húmedas fueron su verdadera escuela, y fue de su biblioteca donde seguramente consiguió la literatura prohibida que completó su aprendizaje en el crimen.

Más allá del transitado expediente de metaforizar la bajeza, la degradación y el carácter sombrío del anarquismo, lo que logra esta localización de una ideología es remitir directamente a un problema territorial que está en el centro del debate público de comienzos de siglo y en el que se conjugan inmigración, cuestión social y nación.

La nación, como en tantos otros textos de la época, es vista como un cuerpo amenazado, en este caso, por el anarquismo, representado por ese germen que es Germán y, sobre todo, por la huelga-gangrena. El sótano es, podría decirse, el laboratorio donde se la incuba, porque el fin último de las "larvas siniestras" que conforman esas sociedades secretas es el “ocio”, el odio a “todo lo que trabaja y crea”. ¿Y qué es la huelga para el texto sino la enfermedad que amenaza con paralizar la nación? Pero la huelga tiene, además del sótano, otro origen (otro laboratorio): "la Europa decrépita la inventó” (490). Y evocamos aquí nuevamente la cita que sirve de epígrafe a este trabajo y el dato de que el mismo año en que se publica Hacia la justicia es sancionada la Ley de Residencia, una ley que intenta contener, mediante la exclusión del territorio nacional, a esa "gangrena”, a esos “enfermos" y “dementes” que vienen de la decrépita Europa.

Sin embargo, hay que decir que Germán, el anarquista, es argentino, como también su padre. Y que en cambio Elbio, el líder de los obreros sanos y libres, es hijo de inmigrante. Es más, en una curiosa torsión de los postulados de Lombroso, el narrador describe cómo lo mejor de Elbio, la garantía de su pureza y vitalidad, reside en el atavismo, en el florecimiento atávico de su sangre vasca. Claro que esta postura en defensa explícita de la continuación del proceso inmigratorio se contrapesa con una advertencia, un leitmotiv amenazante que formula el propio narrador (el propio Sicardi) cuando la huelga todavía no ha concluido:

Pueden irse de esta tierra los que la han contaminado con la doctrina perversa [...] Pueden irse, no hacen falta [...] Y pretenden manchar una nación, cuya grandeza existe por el tesón de los artesanos, que jamás conocieron la huelga violenta sino para condenarla, la huelga que destruye sin rehacer, la tiranía de los psicópatas de imaginación enferma y alma emponzoñada. ¡Váyanse! Esa es planta que no ha de retoñar aquí [... ¡ ¡Váyanse! ¡No contaminen! ¡Vuelvan a la gleba de donde salieron! (563) 
Obviamente esa "gleba” está fuera del territorio nacional y la vehemencia del pedido de expulsión demostraría no tanto una posición contraria a la ley de Residencia como un acuerdo con quienes, desde el gobierno (entre ellos Miguel Cané), explicaban que la ley no iba en contra de los extranjeros sino que procuraba defender al país y a los propios inmigrantes honestos de aquellos que sólo pretendían delinquir y sembrar la anarquía.

El título del volumen, Hacia la justicia, parece hacer referencia a la solución que propone Elbio para resolver los problemas (descarnadamente expuestos en la novela gracias a los discursos de Germán y su literatura) que padecen los obreros: la actividad parlamentaria, la protesta pacífica y sin huelga, y la intervención directa del Estado, con un “Tribunal de arbitraje para obreros” (588), para mediar en la relación entre éstos y sus patrones. Esta propuesta es anunciada en la Plaza de Mayo frente a los obreros que la llenan y que han decidido seguirlo. Allí Elbio explica su modelo de nación, basado en una política independiente y "tercerista” que postula la regulación estatal de las relaciones entre el capital y el trabajo, la implementación de una instrucción buena y barata para todos, y la alianza de espíritu cristiano e "higiene”, “ciencia y Evangelio” (592).

Y si de profilaxis se trata, que mejor que Elbio, el médico, para proteger a la nación de la enfermedad que la amenaza. En su discurso, a la par que denuncia los padecimientos de los obreros frente a los cuales habla, les pide enfáticamente que descarten la huelga como medio de protesta. Pero seguramente su mayor contribución a la derrota del mal es su papel de buen meneur. Su figura parece convocar, en el plano de la ficción, al líder capaz de conmover y dirigir por la buena senda a las multitudes argentinas, neutralizando a los meneurs enfermos como Germán (que pueden fascinar también a los obreros sanos) y logrando transformar a la horda estridente en un "ejército de buenos [que] marcha como soldados, sin gritos, ni tumultos” (593). Los extranjeros indeseables a los que el narrador echa del país son los que no están de acuerdo con ese modelo de nación, sean inmigrantes o argentinos. Los verdaderos “fronterizos" son esos enfermos y dementes que se embanderan en la anarquía y se agrupan en la huelga criminal.

Pero el título del volumen puede ser leído también en relación con otra justicia, la justicia textual que establece de qué modo se resuelven los conflictos y qué sucede con sus protagonistas. Es decir, cómo el relato lleva a cabo su profilaxis. Habíamos dicho que esa aparente equidistancia entra las sectas anarquista y católica era una ilusión. La fórmula que une "evangelio" e "higiene' parece confirmarlo y es paralela a la alianza familiar del epílogo entre Elbio y Ricardo (el líder de los obreros católicos, y hermano de la prometida de Elbio). El cierre de la novela los muestra a ambos, años después, siguiendo con sus actividades (Elbio en el parlamento, Ricardo con su propaganda católica) y viviendo en la misma "casa de anchos corredores" (619), en la misma patria que los anarquistas amenazaron tomar. En cambio, el destino de Germán es (como Lombroso admite debe ser el destino de todo criminal incorregible) la muerte. Y una muerte ejemplar.

Inversamente a lo que ocurre en las sociedades disciplinarias donde, como lo explica Michel Foucault, el castigo es cada vez menos visible y el suplicio deja de ser un espectáculo público, en el mundo de la novela lo esencial es mostrar. Hacer todo visible es la máxima de su pedagogía, de su profilaxis y, por qué no, de su estilo. Llenar de luz la vida de los obreros, las fábricas, los hospitales. Sacar a la luz los sótanos donde medran los criminales. Mostrar la llagas sociales, para justificar el proyecto reformista de Elbio. 
Y coronar su discurso para enseñar a la multitud -entre cuyos integrantes podemos vislumbrar a los lectores- cuál es el destino del incorregible.

La escena de su “ejecución” textual transcurre en la sala de un hospital. Allí, en el delirio final al que lo empuja la tuberculosis, y acompañado solamente por una monja que reza por su alma, Germán hace desfilar los espectros de los anarquistas violentos y otros “vengadores” de la historia reciente: “¡Vera Sassoulitch! [...] ¡Oh vengadora de la miseria! [...]: Ahí va Caserio, ahí pasa Bresci... ¡Déjenlos! Son los vengadores de los ultrajes" (596). Su discurso delirante, asesino y blasfemo confirma hasta en ese final la catadura incorregible de su sangre. “iQuiero la dinamita, la dinamita!” reclama el anarquista en su agonía última. Esa peligrosidad extrema, representada por la bomba, se une a otra mayor: “Aquél era el salvaje que iba a morir rugiendo... como un símbolo de horda” (597). Su voz rugiente evoca el sonido de la dinamita pero también su atavismo criminal y, lo que es peor, a la "horda”. Germán condensa, en el momento de su muerte, la esencia de lo que, para el texto, es la más grave amenaza para el cuerpo de la nación:

No continuó más porque un chorro de sangre caliente saltó de su boca y fue a manchar la toca blanca de la monja. Luego la cara se contrajo en un trismus diabólico y un poco de espuma enrojeció sus labios. Germán Valverde se había quedado quieto y atónito con las pupilas dilatadas. ¡Había muerto, en medio de un silencio de sepulcro! (598)

Germán muere por la boca, por el lugar donde sale su voz blasfema, esa voz a través de la cual fue presentado el personaje en el relato, una voz capaz -como su sangre, por su sangre- de "manchar todo lo puro" y de fascinar a la muchedumbre hasta convertirla en horda, en esa "enfermedad convulsionaria” llamada huelga.

\section{Bibliografía}

Barrows, Susana. Distoring Mirrors. New Haven and London: Yale University Press, 1981.

Cané, Miguel. Expulsión de extranjeros. Buenos Aires: Sarrailh, 1899.

Veyga, Francisco de. “Anarquismo y anarquistas”. Anales del Departamento Nacional de Higiene 20 (Buenos Aires, septiembre de 1897): 437-55.

Foucault, Michael. Vigilar y castigar. Buenos Aires: Siglo xxI, 1992.

Geli, Patricio. "Los anarquistas en el gabinete antropométrico. Anarquismo y antropología en la sociedad argentina del 900”. Entrepasados 2 (Buenos Aires 1992): 7-24.

Gómez, Eusebio. La mala vida en Buenos Aires. Buenos Aires: Juan Roldán, 1908. Herrera, Julio. Anarquismo y defensa social. Buenos Aires: M. A. Rosas, 1917.

Ingenieros, José. La psicopatología en el arte. Obras Completas, t. I. Buenos Aires: Mar Océano, 1961.

Jitrik, Noé. El 80 y su mundo. Buenos Aires: Jorge Álvarez, 1968.

Le Bon, Gustave. Psicología de las multitudes. Madrid, Daniel Jorro Ed., 1911.

Leps, Marie-Christine. Apprehending the Criminal. The Production of Deviance in Nineteenth-Century Discourse. Durham and London: Duke University Press, 1992. Lombroso, Cesare. Los anarquistas. Madrid: Biblioteca Júcar, 1978. 
Montgomery Hunter, Kathryn. Doctors' Stories. The Narrative Structure of Medical Knowledge. Princeton: Princeton University Press, 1991.

Nouzeilles, Gabriela. Ficciones somáticas. Naturalismo, nacionalismo y políticas médicas del cuerpo (Argentina 1880-1910). Rosario: Beatriz Viterbo, 2000.

Oved, Iaacov. El anarquismo y el movimiento obrero en Argentina. México: Siglo xxI, 1978.

Policía de Buenos Aires. Proceso y sus causas de los hechos ocurridos el 1 de mayo de 1909. Buenos Aires: Imprenta de la Policía, 1909.

Posadas, Abel. El libro extraño de Sicardi. Buenos Aires: CEAL, 1968.

Ramos Mejía, José María. Las multitudes argentinas. Buenos Aires: Kraft, 1952.

Rodríguez, Julia E. Encoding the Criminal. Criminology and Science of 'Social Defense' in Modernizing Argentina (1880-1921). Tesis Columbia University, 2000.

Ruibal, Beatriz. Ideología del control social. Buenos Aires 1880-1920. Buenos Aires: CEAL, 1993.

Salessi, Jorge. Médicos, maleantes y maricas. Rosario: Beatriz Viterbo, 1995.

Sicardi, Francisco. Libro extraño. Barcelona: F. Granada y Cía Editores, s/f.

"La vida del delito y la prostitución. Impresiones médico-literarias”. Archivos de Psiquiatría, Criminología y Ciencias Afines 2 (Buenos Aires 1903):11-21.

Stoker, Bram. The Annotated Drácula. Introduction, notes and bibliography by Leonard Wolf. New York: Ballantine Books, 1975.

Terán, Oscar. Vida intelectual en el Buenos Aires fin-de-siglo (1880-1910). Buenos Aires: FCE, 2000.

Vezzetti, Hugo. La locura en Argentina. Buenos Aires: Paidós, 1985.

Vitagliano, Miguel. La novela extraña de Sicardi. Buenos Aires: UBA, 1996.

Zimmermann, Eduardo. Los liberales reformistas. Buenos Aires: Sudamericana/ Universidad de San Andrés, 1995. 